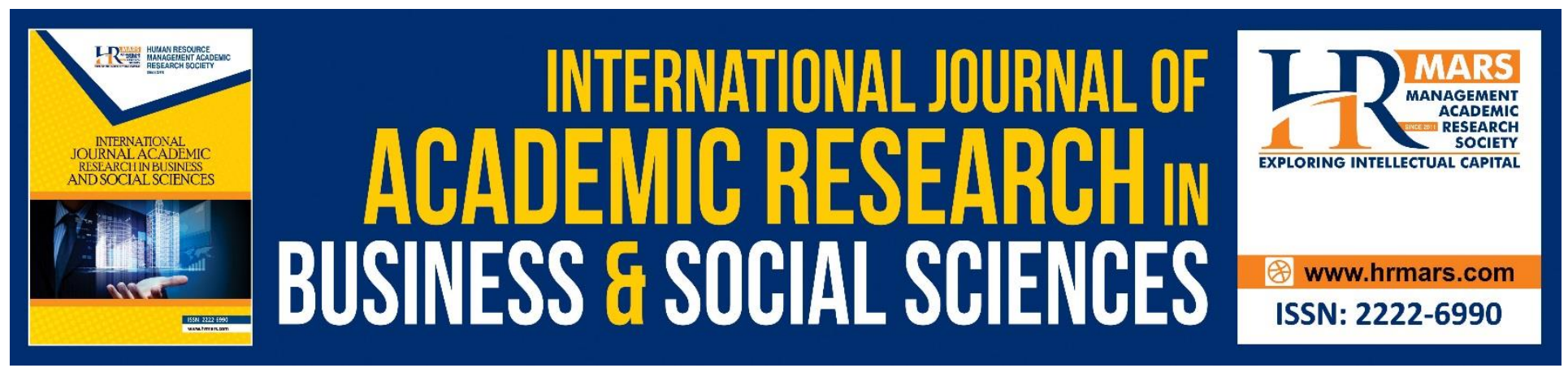

\title{
Study on Employee Silence Behavior: An analysis on Pakistani Family Enterprise
}

Imran Ahmed Shah, Junaid Ahmed Solangi, Aamir Ali Lashari, Abdul Ghaffar Bhatti, Saaherah Alkiany, Azhar Hussain

To Link this Article: http://dx.doi.org/10.6007/IJARBSS/v10-i10/7979 DOI:10.6007/IJARBSS/v10-i10/7979

Received: 28 July 2020, Revised: 25 August 2020, Accepted: 20 September 2020

Published Online: 24 October 2020

In-Text Citation: (Shah, et. al., 2020)

To Cite this Article: Shah, I. A., Solangi, J. A., Lashari, A. A., Bhatti, A. G., Alkiany, S., \& Hussain, A. (2020). Study on Employee Silence Behavior: An analysis on Pakistani Family Enterprise. International Journal of Academic Research in Business and Social Sciences. 10(10), 580-588.

\section{Copyright: (C) 2020 The Author(s)}

Published by Human Resource Management Academic Research Society (www.hrmars.com)

This article is published under the Creative Commons Attribution (CC BY 4.0) license. Anyone may reproduce, distribute, translate and create derivative works of this article (for both commercial and non-commercial purposes), subject to full attribution to the original publication and authors. The full terms of this license may be seen at: http://creativecommons.org/licences/by/4.0/legalcode

Vol. 10, No. 10, 2020, Pg. 580 - 588 http://hrmars.com/index.php/pages/detail/IJARBSS

Full Terms \& Conditions of access and use can be found at http://hrmars.com/index.php/pages/detail/publication-ethics 


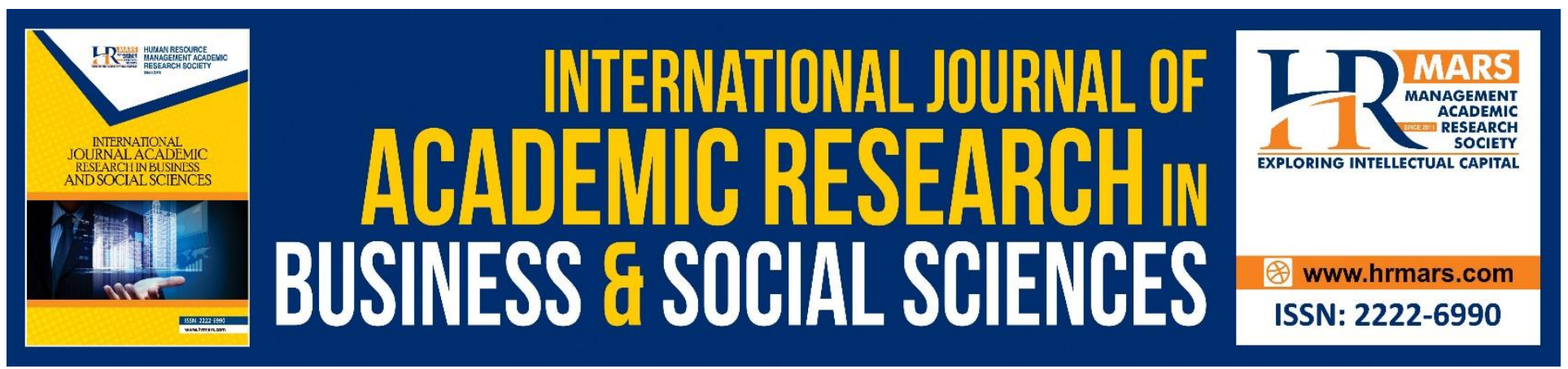

\title{
Study on Employee Silence Behavior: An analysis on Pakistani Family Enterprise
}

\author{
Imran Ahmed Shah ${ }^{1}$, Junaid Ahmed Solangi ${ }^{2}$, Aamir Ali Lashari ${ }^{3}$, \\ Abdul Ghaffar Bhatti ${ }^{4}$, Saaherah Alkiany ${ }^{5}$, Azhar Hussain ${ }^{6}$ \\ 1, School of Management and Economics - University of Electronics Science and Technology of \\ China, ${ }^{2}$ Department. Master Enterprise management, ${ }^{3}$ Department of commerce, Shah Abdul \\ Latif University Khairpur Mirs, ${ }^{4}$ College Education Department, Govt of Sindh, ${ }^{5}$ School of \\ Business Administration, Sichuan University, China, ${ }^{6}$ Sichuan university of science and \\ Engineering, School of Management and Science \\ Email: 1imranshah3117@gmail.com, 2asolangi670@gmail.com, 3alashari.khp@gmail.com, \\ 4asolangi670@gmail.com, ${ }^{5}$ sahiramalkawy@yahoo.com, ${ }^{6}$ azharahmad5522@gmail.com
}

\begin{abstract}
The employees in family business organization put forward ideas, suggestions and opinions based on their ownexperience and knowledge to improve performance and efficacy. Due to various reasons, they sometimes chooseto hide their true thoughts or views. This kind of behavior is defined as employee silence. The article starts froma summary of the existing research on employee silence of family enterprises, such as definition, dimensions, antecedents and measurement methods, puts forward, and provides measurements to improvesustainable development of human resource management.
\end{abstract}

Keywords: Employee Silence, Family Enterprise, Antecedent Variables, Behavior.

\section{Introduction}

In the contemporary enterprise, it is very common to see that staffs only give positive report to leaders of familybusiness for fear of being blamed or do not dare to express their true opinions because of worrying about theirdifferent opinion would provoke the leader; some stuffs cannot express their views or thoughts in the discussionsince fearing of being labeled negatively or just lacking of confidence in their recommendations could adopt byorganizations; when facing with international issues, some staffs obviously have ideas to improve organizationalperformance but they just choose to keep silence because of their indifference to the interests and developmentof the organization, etc. This kind of situation describes common phenomenon of employee silence behavior. It isnot only conducive to bottom-up organizationalinformation exchange and communication, and reduced thequality of top leaders' decision, but also evoke the level of silent employees, work enthusiasm and satisfactiondeclining and affect development of their career. So, in recent years, the silence behavior of employees gets moreand more attention from researchers both 
INTERNATIONAL JOURNAL OF ACADEMIC RESEARCH IN BUSINESS AND SOCIAL SCIENCES Vol. 10, No. 10, 2020, E-ISSN: 2222-6990 @ 2020 HRMARS

at home and abroad. The article comprehensively introduces theresearches of employee silence behavior in family enterprises, discusses the possible disadvantages of currentresearch and future research areas, and hope to attract domestic academia and business to draw attentions to theissue and strengthen the research and practice in this particular field.

\section{Definition and Dimensions of Employee Silence Behavior}

The Definition of Employee Silence Behavior

In the time of economic transition, Chinese family enterprise has faced the situation of lack of congenitalresources controlling by the government and relationship orientation. The earliest research on employee silencebehavior occurred in 1970s, Rosen \&Tesser's research shows that sometimes employees keep silent about theirconcerns. Individuals would limit the spread of bad news as far as possible or simply choose to remain silentbecause they do not want to become bad news communicators for negative message. The reason of thisphenomenon is described as silent effect (also called mum effect). The official presentation of the academicconcept of silence is in 2000; Morrison \& Milliken published a paper in journal of Management Review entitled

Organizational silence: a barrier to change and development in a pluralistic world. According to the article,organizational silence is a collective-level phenomenon, which is the employee's choice to hold back theiropinions and concerns about the organization. Pinder \& Harlos (2001) defined organizational silence aswithholding genuine expression about behavioral, cognitive, and/or affective evaluations of organizationalcircumstances to people who seem capable of changing the situation, focusing more on individual employeesilence as a response to injustice. Dyne et al. (2003) argued that before discussing the concept of employeesilence we need to define the boundary conditions. Firstly, the silence behavior does not include unconscious behaviors. Secondly, we exclude silence behaviors that employees have no related ideas, information andopinions. Finally, we emphasize that employee silence occurs in face-to-face interaction between employees, such as meetings and discussions.

Based on Pakistan's cultural background and refereed to the views of previous researchers, A Chinese scholar Xiaotao (2008) defined employee silence behavior as: employees may raise suggestions, ideas andopinions based on their experience and knowledge so as to improve some works of the department ororganization, due to various reasons they would choose to withhold opinions, or extract and filter their views.

Ma Hui (2010) defined employee silence behavior based on " $4 \mathrm{w}$ " (who silence? Silence to whom? What is theproblem of silence? What is the form?): employees (grassroots employees or managers) could have providedinformation, suggestions and ideas which can help to achieve organization goals to the organization inside andoutside people, but because of various reasons they choose to withhold opinions and refine, filter or exaggeratetheir opinions.

\section{The Dimensions of Employee Silence}

After putting forward the concept of organizational silence, Pinder \&HarloS (2001) further divided it into twotypes: acquiescent silence and quiescent silence. Acquiescent silence refers to holding opinions negatively, whichmeans passive obedience. The quiescent silence refers to holding opinions positively for the purpose ofprotecting the self, based on the fear that consequences of speaking up will be personally unpleasant. Building onthe work of Pinder and Harlos, Dyne (2003) differentiated three types of silence based on employee motives:defensive silence, acquiescent silence and pro- 
social silence. The connotation of the defensive silence andacquiescent silence is the same as the quiescent silence and acquiescent silence which defined by Pinder \&Harlos (2001). But the difference is that Dyne (2003) put forward the pro-social silence based on organizationalcitizenship behavior, he defined it as withholding work-related ideas, information, or opinions with the goal ofbenefiting other people or the organization-based on altruism or cooperative motives. Similar to DefensiveSilence, Pro-Social Silence is based on awareness and consideration of alternatives and the conscious decision towith-hold ideas, information, and opinions. In contrast to Defensive Silence, Pro-Social Silence is motivated byconcern for others, rather than by fear of negative personal consequences that might occur from speaking up.

Owing to the influence of the culture, the structure of the employee silence may not be consistent in differentcountries; therefore, many Chinese scholars on the basis of west research achievements began to research on theemployee silence with Chinese characteristics. Xiaotao (2008) investigated 928 domestic samples andadopted depth interview and semi-structured questionnaire, also draw lessons from foreign related researchresults, divided the employee silence into three dimensions: acquiescent silence, defensive silence andindifference silence, the first two dimensions are just similar to Pinder and Van Dyne's view, but the indifferencesilence rarely mentioned in western literatures, it refers to employees withholding ideas negatively for their lowlevels of commitment and immixture to the organization, that means disregard the interests of the organization.

Min (2009) differentiated three types of silence based on the different macro factors leaded to thebehavior: institutional silence, cultural silence and structural silence. Chunlian (2010), based on summaryof existing research on influencing factors of staff silence behavior: leadership, organization, colleagues, andindividual employees, divided employee silence of Chinese enterprise into three corresponding dimensions:organization system barrier of silence, interpersonal fear silence and low self-esteem individuals silence. Ma Hui (2010) combined " $4 \mathrm{w}$ " theory with the phenomenon of silence according to the behavior change theory, dividedit into double-win silence, no-win silence, silence behavior which damage to individual and benefit the wholeorganization, and damage to the whole organization and benefit individual, etc.

\section{Influencing Factors of Employee Silence Behavior}

The reasons that staffs choose to be silent is various, scholars at home and abroad have studied from severalaspects and achieved some results. Throughout research achievements of predecessors, what kind of elementswould affect employee to be silent can be summarized as individual factor, colleague factor, organizationalleadership factor and culture factor.

\subsection{Individual Factors}

Until now, considering individual factors associated with silence behavior, research mainly focused on gender,internal psychological perception, personality characteristics, self-monitoring and selfesteem level, etc.Gilligan (1982) believed that women's behavior tends to show more relationship orientation, accordingly, whenwomen express their opinions they often need to consider other people's social relations and social acceptanceand, therefore, compared to men, women show more silence behavior. Ryan \&Oestrdch's study shows that the individual factor is the main reason of employee silence. When individuals perceive that expressing opinionswould lead to a bad result or would not produce an expected role and influence, they will choose to remainsilence. Milliken (2003) developed a structure model of employee silence factors by the means of interview. Heconsidered that the key variable is employees' individual psychological perception which mainly includes sixkinds 
INTERNATIONAL JOURNAL OF ACADEMIC RESEARCH IN BUSINESS AND SOCIAL SCIENCES Vol. 10, No. 10, 2020, E-ISSN: 2222-6990 @ 2020 HRMARS

of fear: being negatively labeled or viewed, damaged relationships, belief that speaking up will not make adifference, retaliation or punishment and negative impact on others. Bowen \&Blaekmon (2003) considered thatwhen people feels that his supported views tend to predominate or get the upper hand, he will be more likely tospeak up, otherwise be silent. Empirical study of Lepine \& Van Dyne (1998) shows that the outgoing staff whohave strong sense of responsibility tend to express their opinions, the easy-going employee tend to remain silentfor unwilling to make troubles and destroy the interpersonal relationships. Empirical study of shows that accountability, extroversion has a positive correlation with voice behavior, neuroticism, and opennessis negatively related to voice behavior.

Lepine \&VanDyne, Jeffrey, Premeaux believed that employee's self-esteem level will affect their advice behavior, the low levels are more inclined to protect themselves and do not want to expose themself to be attacked byothers, so they are more likely to choose silence. In an integrated model of Premeaux \& Bedeian (2003), it is tobe proved that the individual self-esteem, self-monitoring, and control of internal and external source wouldaffect the expression behavior in the organization. The externals are more negative and passive, while theinternals have stronger sense of controlling works and therefore are more likely to speak up; individuals with lowlevels of self-esteem are oriented toward self-protection and, thus, are unlikely to put themselves in positions ofvulnerability, and consequently, tend to be silence; the self-monitoring is regulated variable of the model for thereason that individuals with high level of self-monitoring are better at managing their image in public.

\section{Leadership and Organizational Factors}

Morrison \& Milliken (2000) argued that organizational silence is primarily caused by managers; the root cause ismanager's worries of negative feedback and their series of within ideas. Morrison classified managers' innerideas to three categories: employees are selfish and not to be trustworthy, managers mostly understand theimportant issues in the organization and harmony is the embodiment of the organizational health. Korsgaard, Roberson and Rymph (1998) considered that when the negative feedback is from subordinates, it often beconsidered as irrational and be threat to the power of the managers. Just because of the managers' inner ideas andthe fear for the employees' negative feedback information, the organization adopted centralized decisionmakingand lack of upward feedback mechanism and then an atmosphere of silence would formed in the organization.

Edumondson's (2003) study emphasized the important role of leadership in eliminating organizational silence, ifleaders can prompt employees to produce psychological security, it may be conducive to eliminate organizationalsilence.

Huang (2003) found that the openness of leaders is inversely proportional to the frequency of the organizationalsilence, the organization is more open, and the employees are more likely to expression their opinions for theissues. Xiaotao's (2008) empirical research also suggests that employee's trust in the superior hassignificant negative influence on employee silence. In addition, the relationship between superior andsubordinate is also an important factor to affect employee silence. Li Rui, LingWenQuan's (2010) empiricalresearch suggests that perceived supervisor support would significantly improve employees' attitude for job andthe organization, and would increase their enthusiasm for breaking silence and speaking up.

In addition, Chinese scholars began to explore the influence mechanism of the paternalistic leadership whichrooted in Chinese society to affect employee silence behavior. Tang Hongrui (2012) 
INTERNATIONAL JOURNAL OF ACADEMIC RESEARCH IN BUSINESS AND SOCIAL SCIENCES Vol. 10, No. 10, 2020, E-ISSN: 2222-6990 @ 2020 HRMARS

discussed in privateenterprises the relationship between the style of Paternalistic leadership and employee silence and the regulatingrole that superior-inferior relationship plays in, the empirical shows that the Authoritarian leadership of thePaternalistic leadership has a significant positive correlation to employee silence behavior. Sun Fei (2012)proved that the Authority leadership has a significant positive effect on employee silence, and the power distanceand the golden mean separately plays the role of negative and positive regulation in the relationship in his masterthesis. Morrison and Mi11iken (2000) developed a factors model of employ silence behavior, which includes factors ofenvironmental and organizational characteristics which covers the organization atmosphere, the rules andregulations, organizational structure and organizational culture etc., and these factors will lead to employeesilence behavior. Frances Bowen \& Kate B1ackmon's study shows that whether employees put forwardproposals is closely associated with organizational climate (such as unity, trust). The united and trusting climatemakes for information exchange and communication between employees and superiors and among employees. On the contrary, if the organization creates a fear atmosphere, it can make employees afraid to remonstrate andremain silent. Pinder and HarloS' (2001) research shows that unfair environment in the organization can lead toemployee silence. The empirical study of Liu Pengpeng (2011) shows that the employee silence behaviorinfluenced by distributive justice and procedural justice, and the procedural justice is the primary factor, exertinga bigger impact on employee silence, while the interpersonal justice and information justice have no significanteffect on it.

\section{Colleague Factors}

Existing research shows that employees' words and deeds are influenced by the pressure of the collective andemployee silence is a collective phenomenon. Ashforth\&HumPhrey (1995) emphasized the influence of the "label" in organization. When a staff is labeled, other staffs will measured him by the label. Commentedregularly is likely to be negatively labeled, the worst situation would affect employees' promotion opportunitiesand career development. Bowen \& Blackmon (2003) argued that when employees decide whether to givecomments, they largely affected by the perceived colleague's point of view. When they feel their personalviewpoint is one of few people's, for fear of being isolated they would not confess fully of their ideas. Moorhead\&Monranari (1986) believed that employees are more likely to express their views in the case of goodrelationship between employees and colleagues and high group cohesiveness.

\section{Cultural Factors}

Cultural factors is an important antecedent of employee silence behavior, different cultural factor will causedifferent type of silence behavior. Hofstede's study of national culture found that Chinese national culture showsa high power distance, collectivism and long-term tendency. Clugston, Howell and Dorfman's research (2000)shows that when leaders show the authoritarian style, high power distance oriented individuals are more likely toconform to authority and listen to the leader's instructions and then show higher silence behavior. Huang (2003) suggested that the culture of power distance is positively related to employee behavior of withdrawing views.

Many Chinese scholars put forward that the Chinese traditional culture such as Confucian culture, relatively highpower distance, Collectivism concept, such as mianziand guanxi, are the cultural roots of employee silencebehavior under the background of Pakistan. The researchers believed that the golden mean that the Confucianculture pursued and the harmony philosophy drive employees keep 
silence in order to maintain organizational orinterpersonal harmony when they find out problems or have any other objection. To be worldly-wise and playsafe of the Confucian culture, "The squeaky wheel gets the grease", "Names are debts", these old adages alsodrive employees keep silence for fear of retribution and punishment or worrying about lose their trust and respectwhen they want to express their dissent. The cultural consciousness of mianzi and guanxi are deeply rooted in theChinese society, Chinese family businesses would rather put up with or obey relevant opinions and show theacquiescent silence in order to protect themselves or save other's face and avoid the risk of image.

\section{Effect of Employees' Silence Behavior in Family Enterprises}

The Active Effect of Employee Silence Behavior

Research stated that employee silence behavior have some active influences on person and organization inspecial organization environment, such as in family enterprises. Dyne (2003) considered that the pro-socialsilence which based on the motivation of altruism and cooperation is a kind of active silence behavior, and it issame like sportsmanship in the behavior of organizers. They don't care themselves' getting and lost, butbreathing and suffering together with organization and also protecting organization's benefit. Liang Yin (2009)pointed out that some silence is good for organization management, improvement of decision quality and policyexecutive ability, promoting personal observation and thinking fully.

\section{The Negative Effect of Employee Silence Behavior}

The Effect on Family Enterprises

Morison and Milliken (2000) think the silence restrict decision-makers to secure useful information and alsorestrict critical analysis of the view and then will bring down the effectiveness of decisionmaking. At the sametime, if employees kept silence, they will not feedback any information, so, family enterprises cannot observeissues and take corrective actions immediately. It will make organization reforming in vain and declineorganization performance. Van Dyne \& Le Pine (1998), Edmondson (2003) think that employee silence willimpede family businesses' innovation, because this special kind of family business more need employees topoint out new ideas and new thoughts, also query in innovation process. Organization will lost many newinnovation chances if employee did not feedback points and information to the organization. Dundone's test alsostated that voice in organization is good for achieving organization benefit.

\section{The Effect on Personnel}

Morrison and Milliken's (2000) research shows that silence have three types influence on employee: a feel ofnebbish, lack of controlling and cognitive dissonance. When employees have those feelings, it will affectemployee's working satisfaction, commission, work activeness and work press, even lead to asking leave.

Research of Qian Xiaojun and Zhan Xiaoli (2005) stated that good communicating atmosphere in organizationcan increase employees' satisfaction. Xiaotao (2007) though that employee silence will make employeequery the importance of them, decrease the satisfaction to the environment, have a kind of anxiety to body andheart. JiaJuannong (2009) pointed out that long-time silence will make employee have an emotion of "mentalstrike", if so, employee will become "invisible employee" in company. 
INTERNATIONAL JOURNAL OF ACADEMIC RESEARCH IN BUSINESS AND SOCIAL SCIENCES Vol. 10, No. 10, 2020, E-ISSN: 2222-6990 @ 2020 HRMARS

\section{The Measurement and Forecast of Employee Silence Behavior}

The feature of silence is no language and the supplied action clue is obscure, so the measurement of employeesilence behavior will be a challenge in this research field. Now the main measure types are: self-assessment, peerassessment and observation on-site.

Dyne (2003) used peer assessment based on the concept of employee silence to assess colleague's behavior fromthree aspects: acquiescent silence, defensive silence and pro-social silence, each aspect includes five items andadopted Likert scale, in 7 point scale, number 1 means very dissatisfied, number 7 means very satisfaction.

Huang (2003) applied self-assessment to ask employee to assess organization's 27 items from 5 aspects such ascommunication ways, and at last they used average marks to show the silence degree of organization.

Edmondson (2003) adopted observation on site to assess 16 medical team, they set up a working condition, andkeep reaction on file and code to get the result of silence. Milliken (2003) applied semistructure interviewingmethod to work out employee's silence action. Zheng Xiaotao took Chinese employees as research object todevelop employee silence behavior scale by ways of interview and open questionnaire survey. So, there is novery mature measure of silence in academic world. Many researchers are researching and discussing the measureways of employee silence.

Now there are some empirical researches about dependent variable before employee silence. Researchers havestudied the relationship between employee silence and organization support perception, organization trust,leadership trust, organization justice, leadership style and psychological possession. Vakola and Bouradas (2005)studied organizational commitment and job satisfaction as a result of employee silence behavior variables. Butthe study of outcome variable of employee silence is scarcely.

From all above, the article points out that cross-cultural research needs to be strengthened. From the point ofcurrent literature, most studies of employee silence are mainly completed in western countries especially the

United States; studies under the background of Chinese culture are very rarely. The values of Chinese culturesuch as Confucianism, collectivism, high power distance, mianziand renqing, which are different from westernsociety, these all will have influence on employee's silence behavior. Future research would more focus on thebackground of Chinese culture, develop an integrated model and influence factors and outcome variables ofChinese employee's science behavior.

\section{References}

Ashforth, B. E., \& Humphrey, R. H. (1995). Labeling processes in the organization: constructing the individual.In L. L. Cummings, \& B. W. Staw (Eds.), Research in Organizational Behavior, Greenwich, CT: JAI Press, (pp. 413-461).

Bowen, F., \& Blackmon, K. (2003). Spirals of Silence: The Dynamic Effects of Diversity on OrganizationalVoice. Journal of Management Studies, 40(6), 1393-1417. http://dx.doi.org/10.1111/1467-6486.00385

Clugston, M., Howell, J. P., \& Dorfman, P. W. (2000). Does cultural socialization predict multiple bases and fociof commitment? Journal of Management, 26, 5-30.

Duan, J. Y., Wang, C. M., \& Zhong, J. A. (2007). A Research on the Impact of Big Five and Perceived Organizational Justice on Voice Behavior. Journal Psychological Science, 30(I), 19-22. 
INTERNATIONAL JOURNAL OF ACADEMIC RESEARCH IN BUSINESS AND SOCIAL SCIENCES

Vol. 10, No. 10, 2020, E-ISSN: 2222-6990 @ 2020 HRMARS

Dundon, T., Wilkinson, A., Marchington, M., \& Ackers, P. (2004). The Meanings and Purpose of EmployeeVoice. International Journal of Human Resource Management, 15(6), 1149-1170. http://dx.doi.org/10.1080/095851904100016773359

Dyne, L. V., Ang, S., \&Botero, I. C. (2003). Conceptualizing Employee Silence and Employee Voice asMultidimensional Constructs. Journal of Managerial Studies, 9, 1359-1392. http://dx.doi.org/10.1111/1467-6486.00384

Huang, X., Vliert, E. V., \&Vegt, G. V. (2003). Break the silence: do management openness and employeeinvolvement raise employee voice worldwide. Academy of Management Proceedings, 2, 126.

Lepine, J. A., \& Dyne, L. V. (2001). Voice and Cooperative Behavior as Contrasting Forms of ContextualPerformance: Evidence of Differential Relationships with Big Five Personality Characteristics andCognitive Ability. Journal of Applied Psychology, 86(2), 326336.http://dx.doi.org/10.1037/0021-9010.86.2.326

Ma, H. (2010). The Analysis of Employee Silence Based on Behavior Shift. Journal of Applied Psychology, (5),320-323.

Milliken, F. J., Morrison, E. W., \& Hewlin, P. F. (2003). An exploratory study of employee silence; issues thatemployees don't communicate upward and why. Journal of Management Studies, 40(6), 1453-1476.http://dx.doi.org/10.1111/1467-6486.00387

Morrison, E., \& Milliken, F. J. (2000). Organizational silence: a barrier to change and development in apluralistic world. Academy of Management Review, 25, 706-725.

Rosen, S., \&Tesser, A. (1970). On Reluctance to Communicate Undesirable Information: the Mumeffect. Society, 33, 63-253.

Yan, X. H. (2012). The Influence and Mechanisms of Leader-Member Exchange to Voice Behavior. Zhejiangindustry and Commerce University.

Yao, S. J., Deng, Y. N., \& Zheng, J. H. (2009). The Cultural Roots of Employee Silence under the Background ofChina. East China Economic Management, (6), 135-138.

Zhang, M. (2010). A little thinking about employee silence behavior classification. Management Space, 9, 32-33.

Zhao, C. L. (2012). Study on Status of Organizational Silence and Countermeasures under the Chinese Background. Chong Qing University. 